\title{
The Causes of Postoperative Meningitis: The Comparison of Gram-Negative and Gram-Positive Pathogens
}

\author{
Behice KURTARAN ${ }^{1}$, Ferit KUSCU ${ }^{1}$, Aslihan ULU ${ }^{1}$, Ayse Seza INAL ${ }^{1}$, Suheyla KOMUR ${ }^{1}$, Filiz KIBAR ${ }^{2}$, \\ Nuri Eralp CETINALP ${ }^{3}$, Kerem Mazhar OZSOY ${ }^{3}$, Yusuf Kemal ARSLAN ${ }^{4}$, Derviş Mansuri YILMAZ3 \\ Hasan Salih Zeki AKSU ${ }^{1}$, Yesim TASOVA ${ }^{1}$ \\ ${ }^{1}$ Cukurova University, Department of Infectious Diseases, Adana, Turkey \\ ${ }^{2}$ Cukurova University, Department of Microbiology, Adana, Turkey \\ ${ }^{3}$ Cukurova University, Department of Neurosurgery, Adana, Turkey \\ ${ }^{4}$ Cukurova University, Department of Biostatistics, Adana, Turkey
}

Preliminary data from the study was presented in SHEA Spring 2015 Conference, Florida, USA.

Preliminary data from the study was also presented in $5^{\text {th }}$ Türkiye EKMUD Platform 2015, Çeşme, Turkey

\section{ABSTRACT}

AIM: To determine the microbiological etiology in critically ill neurosurgical patients with nosocomial meningitis (NM) and to show the impact of Gram-negative rods and the differences between patient characteristics and the clinical and prognostic measures in Gram-negative and Gram-positive meningitis.

MATERIAL and METHODS: In this prospective, single-center study, we reviewed all adult patients hospitalized during a 12-year period and identified pathogens isolated from post-neurosurgical cases of NM. Demographic, clinical, and treatment characteristics were noted from the medical records.

RESULTS: Of the 134 bacterial NM patients, 78 were male and 56 were female, with a mean age of $46 \pm 15.9$ and a median age of 50 (18-80) years. One hundred and forty-one strains were isolated; 82 (58.2\%) were Gram-negative, 59 (41.8\%) were Grampositive. The most commonly isolated microorganism was Acinetobacter baumannii (34.8\%). Comparison of mortality data shows that the patients who have meningitis with Gram-negative pathogens have higher mortality than with Gram-positives $(p=0.034)$. The duration between surgery and meningitis was shorter in Gram-negative meningitis cases compared to others ( $p=0.045)$ but the duration between the diagnosis and death was shorter in Gram-positive meningitis cases compared to Gram-negatives ( $p=0.017$ ). Cerebrospinal fluid protein and lactate levels were higher and glucose level was lower in cases of NM with Gram-negatives ( $p$ values were respectively, 0.022, 0.039 and 0.049).

CONCLUSION: In NM, Gram-negative pathogens were seen more frequently; $A$. baumanni was the predominant pathogen; and NM caused by Gram-negatives had worse clinical and laboratory characteristic and prognostic outcome than Gram-positives.

KEYWORDS: Etiology, Mortality, Neurosurgery, Postoperative meningitis

\section{INTRODUCTION}

$\mathrm{I}$ $\mathrm{n}$ spite of new antimicrobials and surgical techniques, postoperative meningitis (POM) results in considerable morbidity and mortality, necessitating an organized and thoughtful approach for prevention, diagnosis, and manage- ment. Neurosurgical interventions for trauma or tumors, invasive procedures of the central nervous system, or implants for cerebrospinal fluid (CSF) drainage could end up with POM with an incidence of $0.34 \%-3.1 \%(6,8,22,27)$. The etiology of POM includes a wide spectrum of microorganisms from Gram-positive cocci to Gram-negative bacilli. Although still 
uncommon, Gram-negative organisms seem to be increasing as causative agents of POM $(3,16,17)$. Parodi et al. described the first association between Gram-negative meningitis and neurosurgical operations with the Enterobacter species. Another concern is that the appropriate empirical antimicrobial therapy is essential in preventing morbidity and mortality, and treatment options for Gram-negative bacillary meningitis are limited due to emerging resistance to third-generation cephalosporins (23).

In this report, we aimed to determine the microbiological etiology in critically ill neurosurgical patients with nosocomial meningitis and to show the impact of Gram-negative rods and differences of patient characteristics and the clinical and prognostic measures between Gram-negative and Grampositive meningitis during a 12-year period for patients treated at a tertiary care medical center with a large neurosurgical population.

\section{MATERIAL and METHODS}

\section{Patients and Definitions}

In this prospective, single-center study, we reviewed all the adult patients hospitalized at Cukurova University Medical Center during a 12-year period (from 2004 January until 2015 December) and identified 134 post-neurosurgical cases of nosocomial bacterial meningitis, based on culture.

Demographic, clinical, and treatment characteristics were abstracted from the medical records of each patient. All risk factors for acquisition of nosocomial meningitis (NM) were screened; invasive neurological procedures, head trauma, open and closed skull fractures, posttraumatic CSF leak, and preexisting medical problems. The duration of perioperative hospitalization, duration between surgery and infection, duration between diagnosis of meningitis and mortality, and the duration of treatment were recorded. Microbiological data, including the type of microorganisms isolated and the site of isolation, were also recorded.

Nosocomial meningitis in adult patients was described as below, according to Center for Disease Control and Prevention (CDC) definitions (10).

In poly-microbial culture yields, the case was accepted as Gram-positive meningitis if both pathogens were Grampositive, and Gram-negative meningitis if both pathogens were Gram-negative. The patients whose cultures yielded both Gram-positive and negative microorganisms and fungal pathogens were excluded from the study.

Deaths due to meningitis that developed in the postoperative period were considered as fatalities attributed to POM.

\section{Microbiologic Methods}

CSF was collected for the diagnosis of meningitis. CSF was obtained by lumbar spinal puncture; or from a shunt or a ventricular drain. CSF and blood cultures were taken at the same time. Specimens were transported to the Microbiology Laboratory quickly in a sterile container at room temperature. All CSF samples were processed immediately. If the specimens could not be processed immediately, they were kept at room temperature or placed in an incubator at $37^{\circ} \mathrm{C}$.

Bacterial stain and culture were performed for all CSF specimens submitted to the Department of Microbiology at Cukurova University Hospital Central Laboratory. All CSF specimens were inoculated to a blood agar (Columbia agar with $5 \%$ sheep blood), a chocolate blood agar (Chocolate agar with PolyViteX containing factors $X$ (hemin) and V (NAD), for isolation of fastidious strains belonging to the genera Neisseria, Haemophilus, and Streptococcus pneumoniae), and a thioglycolate broth (for isolation of anaerobic bacteria). Blood agar and chocolate agar were incubated at $37^{\circ} \mathrm{C}$ in $5 \%$ $\mathrm{CO}_{2}$ for a minimum of 96 hours (15). All media were supplied as ready to use from the bioMérieux company (France). For blood cultures, The BACTECTM Systems (Becton Dickinson) were used. These are fully automated microbiology growth and detection systems designed to detect microbial growth from blood specimens.

The isolates were identified using standard microbiological techniques (Gram stain, colony morphology, catalase test, oxidase test, coagulase production, optochin test, $6.5 \%$ $\mathrm{NaCl}$, motility, $\mathrm{H}_{2} \mathrm{~S}$, indole) and also Identification Cards (for Gram-Positive and Gram-Negative bacteria) of the VITEK 2 system (bioMérieux, France).

Antimicrobial susceptibility patterns of isolated microorganisms were determined by using antibiotic susceptibility testing (AST) cards of VITEK 2 system (bioMérieux, France). Susceptibility test results were interpreted according to the Clinical Laboratory Standards Institute (CLSI) by the Advanced Expert System (AES ${ }^{\text {TM }}$ ) of the VITEK 2 system.

\section{Statistical Analysis}

The results were presented as mean \pm standard deviation, median (min-max) for continuous variables, and as $n(\%)$ for categorical variables. Normality was checked for each continuous variable. Comparisons between groups were done using Student's t-test for normally distributed data and the Mann-Whitney $U$ test was used for the not normally distributed data. Comparison of the categorical variables between the groups was done using the Chi-square test. Multiple logistic regression analysis was used to reveal associations between groups (Gram-Positive and Gram-Negative bacteria) and other measurements, with group as the dependent variable. While determining the risk factors of fatality, a multiple logistic regression analysis was also used. A p value $<0.05$ was considered to be statistically significant. Statistical analysis was performed using the IBM SPSS ver. 19 package program (IBM Software, New York, United States).

\section{RESULTS}

During the 12 years of follow up, 134 culture-based POMs were detected. Of the patients, 78 were male and 56 female, with a mean age of $46 \pm 15.9$ and a median age of 50 (18-80) years. All patients had a history of a neurosurgical procedure. Major causes of the procedure were tumors in 70 (52.2\%), severe head injury in 17 (12.6\%) and subarachnoid hemorrhage with 
or without aneurysm in $16(12 \%)$ cases. The demographic and clinical characteristics of 134 culture proven neurosurgical patients who developed POM are shown in Table I.

Microbiological findings were as follows: 141 bacteria were isolated of which $82(58.2 \%)$ were Gram-negative bacteria and $59(41.8 \%)$ were Gram-positive bacteria. Characteristics of illness including microbiological data in patients with nosocomial meningitis are shown in Table II and analysis of clinical follow-up and laboratory parameters of the patients in Table III.

Comparison of POMs caused by Gram-negative and positive pathogens is presented in Tables IVA and IVB. There was no significant difference between the demographic data of meningitis caused by Gram positive or negative pathogens. However, the pathogens' likelihood of being Gram positive was higher in the presence of a shunt. Fatality data showed that the patients who had meningitis with Gram-negative pathogens had higher fatality than with Gram positives $(p=0.034)$. The duration between surgery and meningitis was shorter in Gram-negative meningitis cases compared to Gram-positive meningitis cases $(p=0.045)$, but the duration between the diagnosis and death was shorter in Gram-positive meningitis cases compared to Gram-negative cases $(p=0.017)$. CSF protein and lactate level was higher and glucose level was lower in cases of POM with Gram negatives ( $p$ values were respectively, 0.022, 0.039 and 0.049 ).

Table I: Demographic and Clinical Characteristics of 134 Neurosurgical Patients with POM

\begin{tabular}{|c|c|c|}
\hline & & n (\%) \\
\hline \multirow{2}{*}{ Gender } & Male & $78(58.2)$ \\
\hline & Female & $56(41.8)$ \\
\hline \multirow{8}{*}{ Surgical diagnosis } & Tumor & $70(52.2)$ \\
\hline & Severe head injury & 17(12.6) \\
\hline & Intracranial hemorrhage & $12(9.0)$ \\
\hline & Aneurysm with subarachnoidal hemorrhage & $10(7.5)$ \\
\hline & Subdural / Epidural hematoma & $6(4.5)$ \\
\hline & Aneurysm without hemorrhage & $6(4.5)$ \\
\hline & Shunt dysfunction & $5(3.7)$ \\
\hline & Others & $8(6.0)$ \\
\hline \multirow{2}{*}{ Shunt existence } & Yes & 24(17.9) \\
\hline & No & $110(82.1)$ \\
\hline \multirow{2}{*}{ External drainage therapy } & Yes & $61(45.5)$ \\
\hline & No & 73(54.5) \\
\hline \multirow{2}{*}{ CSF leakage } & Yes & $44(32.8)$ \\
\hline & No & $90(67.2)$ \\
\hline \multirow{2}{*}{ Mechanical ventilation } & Yes & $48(35.8)$ \\
\hline & No & $86(64.2)$ \\
\hline \multirow{2}{*}{ Central venous catheter } & Yes & $88(65.7)$ \\
\hline & No & $46(34.3)$ \\
\hline \multirow{2}{*}{ Steroid usage } & Yes & 99(73.9) \\
\hline & No & $35(26.1)$ \\
\hline \multirow{2}{*}{ Antibiotic usage before surgery } & Yes & $42(31.3)$ \\
\hline & No & $92(68.7)$ \\
\hline \multirow{2}{*}{ Outcome } & Discharge from the hospital & $81(60.4)$ \\
\hline & Death & $53(39.6)$ \\
\hline
\end{tabular}


Parameters found significant on univariate analysis (presence of shunt, CSF lactate, CSF protein, and CSF glucose levels), and the variables that can be clinically significant such as gender and age were evaluated by multivariate analysis and the presence of a shunt was found to be an independent risk factor for Gram-positive meningitis (OR: 3.7 95\% C.I. 1.112.5).

Variables were primarily compared according to survival state when the risk factors were evaluated. Subsequently significant variables (age, procalcitonin, white blood cell, CSF protein, duration of treatment, central venous catheter, gender, Gram characteristic of microorganism) were added to the logistic regression model and risk factors were determined. Via this regression equation, $70 \%$ of the deaths could be explained $\left(R^{2}=0.703\right)$. According to this analysis, being female increases the risk of death 33 times and the meningitis agent being Gram negative also increases the risk of death 26 times (OR: 26.4, 95\% Cl: 1,3-520,2). Each 1-unit increase in CSF protein increases the risk of death 1\% (OR: 1.011 (Cl: 1.001-1.022).

\section{DISCUSSION}

Bacterial meningitis is a life-threatening complication of craniotomy with an incidence of 0.8 to $1.5 \%(15,19)$. One third of the meningitis cases develop approximately in the first week after surgery and one-third in the second week while the other one-third occurs after the second week, in some cases

Table II: Characteristics of Illness Including Microbiologic Data in Patients with POM

\begin{tabular}{|c|c|c|}
\hline \multicolumn{2}{|l|}{ Signs/symptoms of meningitis } & n (\%) \\
\hline \multicolumn{2}{|l|}{ Headache } & $80(59.7)$ \\
\hline \multicolumn{2}{|l|}{ Meningismus } & $108(80.6)$ \\
\hline \multicolumn{2}{|l|}{ Altered mental status } & 113(84.3) \\
\hline \multicolumn{2}{|l|}{ Temperature of $>38.5^{\circ} \mathrm{C}$} & 125(93.3) \\
\hline \multicolumn{2}{|l|}{ Microbiological data } & n (\%) \\
\hline \multicolumn{2}{|l|}{ Lumbar puncture number } & $111(82.8)$ \\
\hline \multirow{3}{*}{ Growth place } & CSF & $88(65.7)$ \\
\hline & Blood & 24(17.9) \\
\hline & CSF and blood & 22(16.4) \\
\hline \multirow{2}{*}{ Number of microorganisms } & Monomicrobial & $127(94.8)$ \\
\hline & Polymicrobial & $7(5.2)$ \\
\hline \multirow{10}{*}{ Gram-negative bacteria isolated from CSF* } & A. baumannii & $49(59.8)$ \\
\hline & $P$. aeruginosa & 11(13.4) \\
\hline & E. coli & $4(4.9)$ \\
\hline & K. pneumoniae & 10(12.2) \\
\hline & E. cloaca & $3(3.7)$ \\
\hline & C. koseri & $1(1.2)$ \\
\hline & M. morganii & $1(1.2)$ \\
\hline & A. xyloxidans & $1(1.2)$ \\
\hline & S. marcescens & $1(1.2)$ \\
\hline & Proteus mirabilis & $1(1.2)$ \\
\hline \multirow{5}{*}{ Gram-positive bacteria isolated from CSF${ }^{*}$} & Coagulase negative Staphylococcus & $33(55.9)$ \\
\hline & S. aureus & 17(28.8) \\
\hline & E. faecalis $D$ & $5(8.5)$ \\
\hline & E. faecium & $3(5.1)$ \\
\hline & S. pneumoniae & $1(1.7)$ \\
\hline
\end{tabular}

*The percentages of the pathogens are calculated in terms of Gram status. 
after several years (15). Patients going through neurosurgical procedures have numerous risk factors for POM. Unfortunately, prognosis of the meningitis in these patients is worse and the fatality rate was $39.6 \%$ in our report.

Experience in surgical techniques and particularly those that decrease CSF leak is associated with minimized POM risk (15). Other factors that are associated with the development of meningitis after craniotomy include concomitant infection at the site of the incision and duration of surgery of more than 4 hours $(12,13,28)$.

Internal ventricular catheters (i.e., cerebrospinal fluid shunts) are commonly used for the treatment of hydrocephalus and the incidence of meningitis-associated cases varies between 4 and $17 \%$. The majority of infections manifest within the first month after the surgery and colonization of the catheter at the time of surgery seems to be the most important cause $(5,26,29)$. Gram-positive microorganisms constitute $60 \%$ of the pathogenic agents. Shunt presence in 24 patients was thought to be a contributing factor. According to the logistic regression analysis, presence of a shunt increased the risk

Table III: Analysis of Clinical Follow Up and Laboratory Parameters of Patients with POM

\begin{tabular}{|c|c|}
\hline Clinical follow up & $\begin{array}{l}\text { Mean } \pm \text { S.D. } \\
\text { Med(min-max) }\end{array}$ \\
\hline $\begin{array}{l}\text { The duration between surgery and } \\
\text { meningitis }\end{array}$ & $\begin{array}{c}14.2 \pm 11.2 \\
11.0(3.0-55.0)\end{array}$ \\
\hline $\begin{array}{l}\text { The duration of hospitalization before } \\
\text { surgery }\end{array}$ & $\begin{array}{c}11.67 \pm 13.9 \\
8.0(0.0-99.0)\end{array}$ \\
\hline The duration of hospitalization in ICU & $\begin{array}{c}39.1 \pm 29.1 \\
35.0(0.0-177.0)\end{array}$ \\
\hline The total duration of hospitalization & $\begin{array}{c}49.9 \pm 30.9 \\
44.0(8.0-177.0)\end{array}$ \\
\hline $\begin{array}{l}\text { The duration between diagnosis and } \\
\text { death }\end{array}$ & $\begin{array}{c}27.0 \pm 24.8 \\
24.0(2.0-128.0)\end{array}$ \\
\hline Laboratory findings & $\begin{array}{l}\text { Mean } \pm S . D . \\
\text { Med(min-max) }\end{array}$ \\
\hline $\begin{array}{l}\text { Peripheral WBC count (median cells/ } \\
\mathrm{mm}^{3} \mathrm{X} 10^{3} \text { ) }\end{array}$ & $\begin{array}{c}15337 \pm 6331 \\
15300(4300-31000)\end{array}$ \\
\hline CRP (mg/L) & $\begin{array}{c}13.3 \pm 10.9 \\
11.2(0.5-48.9)\end{array}$ \\
\hline CSF WBC count (median cells $/ \mathrm{mm}^{3}$ ) & $\begin{array}{c}659.7 \pm 817.3 \\
260.0(30.0-3500.0)\end{array}$ \\
\hline CSF protein level (mean mg/dL) & $\begin{array}{c}187.1 \pm 154.6 \\
132.0(21.0-658.0)\end{array}$ \\
\hline CSF glucose level (mean mg/dL) & $\begin{array}{c}47.2 \pm 35.4 \\
42.0(2.0-164.0)\end{array}$ \\
\hline CSF lactate level (median mg/dL) & $\begin{array}{c}7.9 \pm 4.8 \\
7.0(1.7-23.0)\end{array}$ \\
\hline
\end{tabular}

of meningitis 3.7 times. In our study, for meningitis due to Gram-positive microorganisms, the mean and median time between surgery and infection was found to be 16.4 days and 13 days respectively and this supports the literature data. However, in meningitis due to Gram-negative pathogens, this duration (mean and median times were 11.2 and 10 days) was interestingly shorter. Neither high virulence of the pathogens nor the high probability of resistance to empirical treatment options of the microorganisms yielded in Gramnegative meningitis cases, with $A$. baumannii, $P$. aeruginosa and $K$. pneumonia the three most common pathogens, could be interpreted as a cause of this finding, based on this study. Another result of the study was that the time between meningitis and death was shorter in Gram-positive meningitis compared to Gram-negative meningitis (median time was 7.5 days and 28 days in Gram-positive and Gram-negative meningitis, respectively). Meningitis due to Gram-positive microorganisms was more common in patients with shunts and it is possible that complications secondary to shunts such as obstruction could have contributed to this finding. The late diagnosis of Gram-positive meningitis could have been another reason for these patients' quicker death.

The diagnosis of nosocomial bacterial meningitis is made on the basis of the results of a CSF culture and aerobic and anaerobic culturing techniques are obligatory. However, cultures require prolonged incubation before being confirmed as negative, and results may be negative in patients who have received previous antimicrobial therapy (28). Failure to perform lumbar puncture to all of the patients because of contraindications, the empirical treatment starting before the diagnostic procedure and preventing a positive culture result, and lack of awareness can cause delay of the POM diagnosis $(1,2)$. We only included the patients with positive yields in CSF and/or blood cultures in our study. However, it is obvious that the total number of NM cases is larger. We should therefore say openly that the prevalence of meningitis we presented is lower than the actual rate. Nevertheless, the main aim of our study being evaluation of POM according to the pathogenic agents, we can say that the study still serves its purpose.

Among adults, gram-negative bacillary meningitis is known as an uncommon infection associated with advanced age, immunosuppression, and neurosurgery $(14,30,31)$, but NM due to Gram-negative rods were the most frequent cases identified in this series. POM patients had high a mortality rate. The introduction of epidemic $A$. baumannii into a neurosurgical unit is a severe risk factor for patients undergoing neurosurgical procedures. Nosocomial Gram-negative bacillary meningitis and bacteremia also occurred in a patient who was receiving intrathecal and intravenous amphotericin B (24). In our hospital, the predominant causative pathogen is $A$. baumannii and it has been endemic in our Intensive Care Unit (ICU)'s in recent years. The fact that $A$. baumannii was the most frequent cause of POM and the Gram-negative dominance were therefore not a surprise to us.

As the clinical manifestations of Acinetobacter meningitis are similar to those of other Gram-negative bacillary meningitis cases, the diagnosis can only be confirmed by bacterial 
culture. Resistance to multiple antibiotics, including thirdgeneration cephalosporins, is frequently seen in patients with nosocomial Acinetobacter meningitis, and carbapenems seems to be the antibiotic of choice for this potentially fatal central nervous system infection $(4,9,11,18,20)$.

Clinical suspicion is the first step in diagnosing nosocomial bacterial meningitis and prompt diagnostic investigation and antimicrobial therapy are needed. Although non-specific, a decreased level of consciousness and fever are the most important clinical features, $(1,30,31)$, but they are hard to recognize in patients who have just undergone neurosurgery, or who have an underlying disease that interferes with their level of consciousness (21). Signs of meningeal irritation are seen in less than $50 \%$ of patients with infections associated with CSF shunts and they may cause nonspecific symptoms such as low-grade fever or general malaise $(5,21,29)$. In a recent study evaluating 62 adult bacterial meningitis patients who had undergone surgery, fever and disturbance of consciousness were the most common symptoms (30). Symptoms and signs associated with peritonitis or bacteremia where the distal portion of the shunt is can also be seen $(5,21,29)$. As the clinical course in nosocomial meningitis tends to be indolent and clinical findings such as headache and fever might be overlooked in post-neurosurgical patients, the diagnosis of hospital-acquired bacterial meningitis can be difficult (31). In our study, there was no difference between the clinical

Table IVA: Comparison of Demographic, Clinical and Prognostic Features of Gram-Negative and Positive POMs

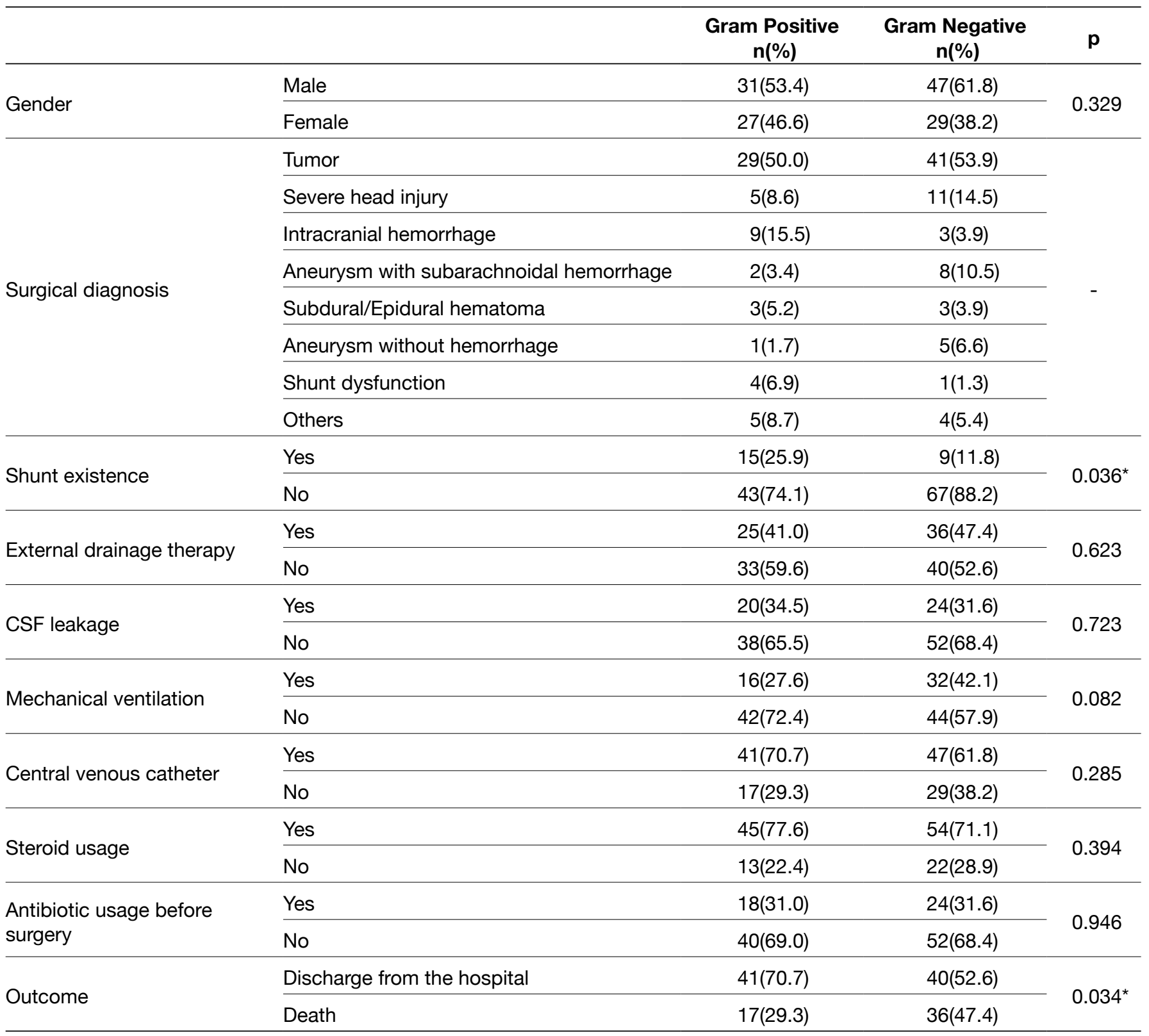

${ }^{*} p<0.05$. 
tables of Gram-negative and positive meningitis. This situation justifies the wide spectrum empirical therapy approach.

In a prospective cohort of 230 patients, severe disturbances in the CSF of patients with external drains limited the value of routine CSF analysis for prediction or diagnosis of external drainage-related bacterial meningitis (25). In our study, CSF findings of patients with external drainage were not evaluated further. However, it was noteworthy that there was no difference in the causative pathogens and Gram negatives were slightly more frequent. On the other hand, we found a significant relationship between presence of a shunt and Gram-positive meningitis on univariate and multivariate analysis.

In the evaluation of CSF findings based on causatives, parameters like lactate, protein and glucose levels were found to be different on univariate analysis. CSF protein and lactate levels were higher while glucose levels were lower in Gramnegative meningitis. It $\mathrm{s}$ not appropriate to give thresholds for these parameters and also its hard to comment about the pathophysiology. However, it can be interpreted from this study that Gram-negative microorganisms change CSF analysis reports more prominently.
Finally, maybe the most important result of this study is that fatality of the meningitis caused by Gram-negative microorganisms was higher than with Gram-positives (fatality comparison between causative agents had statistical significance; fatality was $47.4 \%$ and $29.3 \%$ in Gram-negative and -positive meningitis respectively). It might not be possible to tie this result to microorganism-associated factors but it can be said that drug resistance is tending to increase all over the world and particularly the spread of carbapenem-resistant species contribute to this increase $(1,7,9)$.

Our study has two important limitations. Negative CSF cultures occur in $11-30 \%$ and may be more common in nosocomial meningitis and the first limitation was including only patients who had positive CSF cultures $(25,28)$. Additionally, patients who may not undergo lumbar puncture, such as brain abscess or postoperative intracranial hemorrhage, can result in negative CSF cultures and these patient groups being partly represented in our study can result in an underestimation of the rate of CSF parameters for comparison $(1,28)$. Another issue is that the prognosis of polymicrobial meningitis was not interpreted because of having a low number of cases.

Table IVB: Comparison of Demographic, Clinical and Prognostic Features of Gram-Negative and Positive POMs

\begin{tabular}{|c|c|c|c|}
\hline & $\begin{array}{c}\text { Gram Positive Mean } \pm \text { S.D. } \\
\text { Med(min-max) }\end{array}$ & $\begin{array}{c}\text { Gram Negative Mean } \pm \text { S.D. } \\
\text { Med(min-max) }\end{array}$ & $\mathbf{p}$ \\
\hline Age of patients & $\begin{array}{c}43.7 \pm 17.1 \\
48.5(18-75)\end{array}$ & $\begin{array}{l}47.7 \pm 14.8 \\
51(19-80)\end{array}$ & 0.152 \\
\hline The duration between surgery and meningitis & $\begin{array}{c}16.4 \pm 12.6 \\
13.0(3.0-55.0)\end{array}$ & $\begin{array}{c}11.2 \pm 6.7 \\
10.0(3.0-33.0)\end{array}$ & $0.045^{*}$ \\
\hline The duration of hospitalization before surgery & $\begin{array}{l}11.53 \pm 13.3 \\
9.0(0.0-77.0)\end{array}$ & $\begin{array}{c}11.8 \pm 14.4 \\
8.0(0.0-99.0)\end{array}$ & 0.708 \\
\hline The duration of hospitalization in ICU & $\begin{array}{c}37.9 \pm 35.5 \\
25.0(0.0-177.0)\end{array}$ & $\begin{array}{c}40.0 \pm 23.1 \\
38.0(0.0-87.0)\end{array}$ & 0.720 \\
\hline The total duration of hospitalization & $\begin{array}{c}52.0 \pm 37.2 \\
45.0(80-177.0)\end{array}$ & $\begin{array}{c}48.4 \pm 25.3 \\
42.5(10.0-140.0)\end{array}$ & 0.966 \\
\hline The duration between diagnosis and death & $\begin{array}{c}14.6 \pm 13.3 \\
7.5(2.0-46.0)\end{array}$ & $\begin{array}{c}33.3 \pm 27.6 \\
29.0(2.0-128.0)\end{array}$ & $0.017^{\star}$ \\
\hline Peripheral WBC count (median cells $/ \mathrm{mm}^{3} \times 10^{3}$ ) & $\begin{array}{c}15335 \pm 6754 \\
15300(4300-31000)\end{array}$ & $\begin{array}{c}15337 \pm 6022 \\
14800(5300-27100)\end{array}$ & 0.999 \\
\hline CRP (mg/L) & $\begin{array}{c}13.2 \pm 11.7 \\
10.9(0.7-45.4)\end{array}$ & $\begin{array}{c}13.4 \pm 10.4 \\
11.4(0.5-48.9)\end{array}$ & 0.674 \\
\hline CSF WBC count (median cells $/ \mathrm{mm}^{3}$ ) & $\begin{array}{c}652.7 \pm 842.9 \\
240.0(30.0-3500.0)\end{array}$ & $\begin{array}{c}665.0 \pm 804.6 \\
320.0(30.0-3250.0)\end{array}$ & 0.923 \\
\hline CSF protein level (mean mg/dL) & $\begin{array}{c}152.7 \pm 139.6 \\
102.0(34.0-658.0)\end{array}$ & $\begin{array}{c}211.8 \pm 161.3 \\
162.0(21.0-632.0)\end{array}$ & $0.022^{*}$ \\
\hline CSF glucose level (mean mg/dL) & $\begin{array}{c}53.1 \pm 29.7 \\
45.0(10.0-164.0)\end{array}$ & $\begin{array}{c}44.0 \pm 38.4 \\
28.0(2.0-148.0)\end{array}$ & $0.049^{*}$ \\
\hline CSF lactate level (median $\mathrm{mg} / \mathrm{dL}$ ) & $\begin{array}{c}6.8 \pm 3.4 \\
6.3(2.1-20.0)\end{array}$ & $\begin{array}{c}8.8 \pm 5.5 \\
7.8(1.7-23.0)\end{array}$ & $0.039^{*}$ \\
\hline
\end{tabular}

${ }^{*} p<0.05$ 


\section{- CONCLUSION}

In POMs, Gram-negative pathogens were seen more frequently; A.baumanni was the predominant pathogen; meningitis developed relatively faster, CSF findings were affected more prominently, and the fatality rate was higher in meningitis due to Gram-negative pathogens. Our study supports the known association between Gram-positive meningitis and shunt use. The worldwide antibiotic resistance, which could have produced serious problems in this high fatality group, and the basic role of infection control in the management of the disease should not be forgotten.

\section{- REFERENCES}

1. Bardak Ozcem S, Sipahi OR: An updated approach to healthcare-associated meningitis. Expert Rev Anti Infect Ther 12(3):333-342, 2014

2. Beer R, Lackner P, Pfausler B, Schmutzhard E: Nosocomial ventriculitis and meningitis in neurocritical care patients. $J$ Neurol 255:1617-1624, 2008

3. Berk SL, McCabe WR: Meningitis caused by gram-negative bacilli. Ann Intern Med 93:253-260, 1980

4. Chang WN, Chuang YC, Lu CH: Acinetobacter meningitis: four nosocomial cases. J Formos Med Assoc 98(3):214-217, 1999

5. Conen A, Walti LN, Merlo A, Fluckiger U, Battegay M, Trampuz A: Characteristics and treatment outcome of cerebrospinal fluid shunt-associated infections in adults: A retrospective analysis over an 11-year period. Clin Infect Dis 47:73-82, 2008

6. Dettenkofer M, Ebner W, Els T, Babikir R, Lücking C, Pelz K, Rüden H, Daschner F: Surveillance of nosocomial infections in a neurology intensive care unit. J Neurol 248:959-964, 2001

7. Erdem I, Hakan T, Ceran N, Metin F, Senbayrak Akcay S, Kucukercan M, Berkman MZ, Goktas P: Clinical features, laboratory data, management and the risk factors that affect the mortality in patients with postoperative meningitis. Neurol India 56(4):433-437, 2008

8. Federico $G$, Tumbarello M, Spanu T, Roselli R, lacoangeli M, Scerrati M, Tacconelli E: Risk factors and prognostic indicators of bacterial meningitis in a cohort of 3580 postneurosurgical patients. Scand J Infect Dis 33: 533-537, 2001

9. Garnacho-Montero J, Amaya-Villar R: Multiresistant Acinetobacter baumannii infections: Epidemiology and management. Curr Opin Infect Dis 23: 332-339, 2010

10. Horan TC, Andrus M, Dudeck MA: CDC/NHSN surveillance definition of health care-associated infection and criteria for specific types of infections in the acute care setting. Am J Infect Control 36:309-332, 2008

11. Kim BN, Peleg AY, Lodise TP, Lipman J, Li J, Nation R, Paterson DL: Management of meningitis due to antibioticresistant Acinetobacter species. Lancet Infect Dis 9:245-255, 2009

12. Kim HI, Kim SW, Park GY, Kwon EG, Kim HH, Jeong JY, Chang $\mathrm{HH}$, Lee JM, Kim NS: The causes and treatment outcomes of 91 patients with adult nosocomial meningitis. Korean J Intern Med 27:171-179, 2012

13. Kim HY, Kim YK, Uh Y, Whang K, Jeong HR, Choi HJ, Son HJ, Jin HY, Choi SI, Kim HB, Kim ES, Park YS, Cho YK, Park SY, Song YG, Kim JM: Risk factors for neurosurgical site infections after craniotomy: A nationwide prospective multicenter study in 2008. Korean J Nosocomial Infect Control 14:88-97, 2009
14. Kim YK, Kim HY, Kim ES, Kim HB, Uh Y, Jung SY, Jin HY, Cho YK, Kim EC, Lee YS, Oh HB: The Korean surgical site infection surveillance system report, 2009. Korean J Nosocomial Infect Control 15:1-13, 2010

15. Korinek AM, Baugnon T, Golmard JL, van Effenterre R, Coriat $P$, Puybasset L: Risk factors for adult nosocomial meningitis after craniotomy: Role of antibiotic prophylaxis. Neurosurgery 59: 126-133, 2006

16. Logigan C, Mihalache D, Turcu T: Clinical study of 57 cases of nosocomial meningitis. J Prevent Med 16:59-68, 2008

17. Mancebo J, Domingo P, Blanch L, Coll P, Net A, Nolla J: Post-neurosurgical and spontaneous gram-negative bacillary meningitis in adults. Scand J Infect Dis 18:533-538, 1986

18. Maragakis LL, Perl TM: Acinetobacter baumannii: Epidemiology, antimicrobial resistance, and treatment options. Clin Infect Dis 46: 1254-1263, 2008

19. McClelland S III, Hall WA: Postoperative central nervous system infection: Incidence and associated factors in 2111 neurosurgical procedures. Clin Infect Dis 45:55-59, 2007

20. Metan G, Alp E, Aygen B, Sumerkan B: Carbapenem-resistant Acinetobacter baumannii: An emerging threat for patients with post-neurosurgical meningitis Int J Antimicrob Agents 29(1): 112-113, 2007

21. Muttaiyah S, Ritchie S, Upton A, Roberts S: Clinical parameters do not predict infection in patients with external ventricular drains: A retrospective observational study of daily cerebrospinal fluid analysis. J Med Microbiol 57:207-209, 2008

22. Palabiyikoglu I, Tekeli E, Cokca F, Akan O, Unal N, Erberktas I, Lale S, Kiraz S: Nosocomial meningitis in a university hospital between 1993 and 2002. J Hosp Infect 62(1):94-97, 2006

23. Parodi S, Lechner A, Osih R, Vespa P, Pegues D: Nosocomial enterobacter meningitis: Risk factors, management, and treatment outcomes. Clin Infect Dis 37: 159-166, 2003

24. Sarubbi FA Jr, Wilson B, Lee M, Brokopp C: Nosocomial meningitis and bacteremia due to contaminated amphotericin B. JAMA 239(5):416-418, 1978

25. Schade RP, Schinkel J, Roelandse FW, Geskus RB, Visser LG, van Dijk MC, Vermoolen JHC, van Pelt H, Kuijper EJ: Lack of value of routine analysis of cerebrospinal fluid for prediction and diagnosis of external drainage-related bacterial meningitis. J Neurosurg 104:101-108, 2006

26. Schade RP, Schinkel J, Visser LG, Van Dijk JM, Voormolen $\mathrm{JH}$, Kuijper EJ: Bacterial meningitis caused by the use of ventricular or lumbar cerebrospinal fluid catheters. J Neurosurg 102:229-234, 2005

27. van Aken MO, de Marie S, van der Lely AJ, Singh $R$, van den Berge JH, Poublon RM, Fokens WJ, Lamberts SWJ, de Herder WW: Risk factors for meningitis after transsphenoidal surgery. Clin Infect Dis 25:852-856, 1997

28. van de Beek D, Drake JM, Tunkel AR: Nosocomial bacterial meningitis. N Engl J Med 362:146-154, 2010

29. Vinchon M, Dhellemmes P: Cerebrospinal fluid shunt infection: Risk factors and long-term follow-up. Childs Nerv Syst 22: 692-697, 2006

30. Wang KW, Chang WN, Huang CR, Tsai NW, Tsui HW, Wang HC, Su TM, Rau CS, Cheng BC, Chang CS, Chuang YC, Liliang PC, Tsai YD, Lu CH: Post-neurosurgical nosocomial bacterial meningitis in adults: Microbiology, clinical features, and outcomes. J Clin Neurosci 12: 647-650, 2005

31. Weisfelt M, van de Beek D, Spanjaard L, de Gans J: Nosocomial bacterial meningitis in adults: A prospective series of 50 cases. J Hosp Infect 66:71-78, 2007 